\title{
As escritas de si na privação da liberdade: jovens em conflito com a lei arquivando a própria vida*
}

\author{
NILDA STECANELA \\ Universidade de Caxias do Sul \\ Rede Municipal de Ensino de Caxias do Sul
}

EVALDO ANTONIO KUIAVA

Universidade de Caxias do Sul

\section{INTRODUÇÃO}

O foco deste artigo volta-se para os percursos reflexivos produzidos numa pesquisa realizada com jovens em conflito com a lei e socializados em contextos de privação da liberdade. Tem como objetivo analisar as representações ${ }^{1}$ que nove jovens, situados na faixa etária dos 18 aos 21 anos, têm sobre sua situação juvenil, considerando as narrativas de si como material privilegiado para reflexão. Procura

* Além dos autores deste texto, a pesquisa conta com a colaboração de outros pesquisadores: Carmem Maria Craidy - PPGEDU/UFRGS; Delcio Antonio Agliardi - Associação Criança Feliz; Morgana Bozza - PIBIC/CNPq a/c 2010; Franciele Becher - PIBIC/ CNPq (2008 a 2009).

1 Utilizamos o conceito de representação abordado por Chartier (1988; 1991), no qual o autor afirma que as representações configuram resultado dos processos nos quais os indivíduos se envolvem em seus percursos de vida. Mediante sua interiorização, apropriação ou interpretação, como acontecimentos significativos, esses processos reelaborados ganham novos sentidos, ou seja, novas representações para cada sujeito que pertence a uma determinada categoria, grupo ou classe social. 
escavar as subjetividades construídas nos processos de estigmatização associados aos percursos pelas rotas do risco, assim como os indícios e o grau de identificação que cada jovem tem com suas identidades como: jovens, alunos, prisioneiros ou outras.

A construção dos dados valeu-se do recurso à escrita de cartas como suporte para as escritas de si, por meio da qual os jovens produzem narrativas sobre o cotidiano juvenil na privação da liberdade. Buscamos sustentação nas bases epistemológicas, teóricas e metodológicas da pesquisa (auto)biográfica, ${ }^{2}$ considerando as contribuições de Marie-Chistine Josso e Maria da Conceição Passeggi, em combinação com autores que articulam (auto)biografia em contextos prisionais, a exemplo de Michel Foucault, Heleusa Figueira Câmara, José Machado Pais e Philippe Artières. Concordamos que esta perspectiva metodológica descortina seus sentidos à medida que possibilita a construção de narrativas sobre si, permitindo interpretações tanto dos aspectos individuais como das dimensões sociais envolvidas no contexto de sua produção.

O trânsito pelas rotas do cotidiano juvenil constitui um desafio já enfrentado em outros momentos de nossas trajetórias, seja pelo recorte geracional da ótica do mundo adulto e do lugar de educadores da educação básica, seja através da investigação social envolvendo as culturas juvenis e as aprendizagens não escolares (Stecanela, 2010). Entretanto, penetrar nos entrelaçamentos espaçotemporais das narrativas de si protagonizadas por jovens em privação de liberdade representa, à primeira vista, quase um atrevimento, consideradas as adversidades para a apreensão dos conteúdos de vida desses atores sociais em rotas de colisão com a lei.

Baseados nas escritas juvenis sobre o cotidiano prisional - o antes, o durante e o depois do ato infracional - tentamos decifrar os seus percursos e os seus projetos de vida. O método (auto)biográfico e suas potencialidades na produção de narrativas reflexivas forneceram o substrato empírico para as análises que ora apresentamos, as quais são construídas com base nas unidades de sentido, tomadas das cartas que os jovens escreveram aos pesquisadores, no período de abril de 2009 a janeiro de 2010. ${ }^{3}$ Partimos do pressuposto de que a pesquisa (auto)biográfica se funda nas relações que os sujeitos estabelecem a partir das suas experiências, levando-os a articular em suas narrativas, pelo menos, três dimensões do vivido: ter experiência, fazer experiência e pensar a experiência. É nesse sentido que Josso (2010) sublinha a abordagem (auto)biográfica como um processo simultâneo de investigação e de formação. Segundo ela, ao narrar seus percursos, os sujeitos tomam consciência de si e de suas aprendizagens, passando a desempenhar, simultaneamente, o papel

2 Adotamos os parênteses, seguindo orientação das edições do Congresso Internacional de Pesquisa (Auto)Biográfica (CIPA), como forma de chamar atenção sobre dois tipos de fontes nas pesquisas educacionais: as biográficas e as autobiográficas (Passeggi, 2010, p. 108).

3 Alguns jovens prolongaram seus espaços-tempos de escrita, mantendo o fluxo ativo das correspondências. 
de atores e de investigadores de suas próprias vidas, reforçando o caráter reflexivo possibilitado por este método de investigação.

A pesquisa está sendo desenvolvida com jovens em conflito com a lei, do sexo masculino, internos numa instituição de caráter socioeducativo, localizada no interior do estado do Rio Grande do Sul. O estudo iniciou-se em 2008, com a busca da autorização judicial para a abordagem dos jovens, assim como através da submissão do projeto ao Comitê de Ética da Universidade de Caxias do Sul. Esses procedimentos respondem às exigências do Estatuto da Criança e do Adolescente, o qual regulamenta a Doutrina da Proteção Integral da ONU, estabelecendo parâmetros para a realização de intervenções junto a unidades socioeducativas.

Em conjunto com uma etnografia da instituição-cenário, um processo de sensibilização foi realizado no início de 2009 com a projeção do filme Escritores da liberdade. Ao todo foram realizadas quatro sessões, distribuindo os cerca de oitenta internos em grupos de no máximo vinte jovens, acompanhados dos monitores e dos professores, nos espaços da escola inserida na instituição. ${ }^{4}$ A partir da projeção dos objetivos da pesquisa e dos extratos do filme, procedemos com o convite para participação do estudo, com esclarecimentos sobre os fluxos das cartas, entrega de envelopes, papel e caneta. ${ }^{5}$ Alguns jovens devolveram os envelopes logo após o término da projeção demonstrando não ter interesse em participar, poucos fizeram perguntas sobre os destinos da pesquisa e vários manifestaram imediatamente $o$ desejo de contribuir com o estudo. Explicamos que a participação era voluntária e que a continuidade no fluxo da escrita das cartas poderia ser interrompida a qualquer momento, considerando a escolha de cada jovem. As interações foram satisfatórias, constituindo uma amostra qualitativa de aproximadamente dez por cento do total da população alvo. Em quase todas as vezes em que íamos até a instituição para levar as respostas às correspondências, havia cartas escritas pelos jovens, embora tenhamos vivenciado alguns períodos de baixa nos fluxos, quase sempre associados a alguns tensionamentos vividos no interior da instituição, seja pela chegada de novos jovens ou pelo não retorno daqueles que pegavam externa. ${ }^{6}$

4 O Centro de Atendimento Socioeducativo (CASE) combina ações de duas Secretarias de Estado: a Segurança Pública e a Educação. No espaço reservado à educação, situa-se uma escola, caracterizada como uma escola inserida, cuja organização curricular contempla quatro etapas do ensino fundamental e três séries do ensino médio.

5 As canetas foram entregues após remoção da estrutura plástica, uma vez que o regulamento do CASE não permite que os jovens portem canetas com estrutura completa pois elas podem se converter em suporte, ou seja, em instrumento que pode se constituir numa arma.

6 Pegar externa é uma expressão utilizada para referir-se ao direito a sair da instituição nos finais de semana. Vários jovens que usufruíram desse direito não retornaram ao CASE e passaram a ser considerados foragidos. 
Os arquivos da pesquisa são compostos por um acervo significativo. Até maio de 2010 eram 97 cartas trocadas entre quatro pesquisadores e nove jovens, totalizando 140 páginas de narrativas digitadas em folha A4, acrescidas de 150 páginas, também em $\mathrm{A} 4$, com a transcrição das entrevistas, realizadas com três jovens. Estas últimas fazem parte da segunda fase da pesquisa que incluiu entrevistas em profundidade com periodicidade semanal, ao longo de dois meses, envolvendo três jovens participantes da amostra anterior.

Numa atitude quase detetivesca, construímos nossa própria narrativa, tecendo um texto descritivo e analítico, combinando três dimensões do diálogo, no qual procuramos estabelecer uma conversa entre nossos: interlocutores empíricos, interlocutores teóricos e objetivos de pesquisa (Stecanela, 2010). Apresentamos a seguir uma primeira incursão analítica nos textos dos jovens em tentativas de identificação de algumas categorias emergentes do nosso estudo. Antecipa-se que, no exercício das escritas de si, os jovens participantes da pesquisa fazem produções discursivas que possibilitam: as percepções de si; a explicitação dos seus projetos de futuro; a evocação de memórias nas temporalidades remotas da infância e do período imediatamente anterior à reclusão, relacionando-as com as vivências do presente. Através de uma escrita estimulada pela pesquisa, por meio das cartas, os jovens sistematizaram uma ação humana não intencional, uma vez que narrar a própria vida, fazer um balanço de ações e acontecimentos constitui uma ação humana espontânea, praticada com frequência no cotidiano dos indivíduos. Entretanto, Passeggi (2010, p. 104) sublinha que "uma longa caminhada separa a espontaneidade dessa ação e o ato deliberado de escrever sobre a própria vida: tanto do ponto de vista da filogênese, quanto da ontogênese". Para a autora, "os instrumentos tornaram-se cada vez mais sofisticados e as biografias reservadas inicialmente a fatos memoráveis de personalidades históricas, democratizaram-se”. Ressalta ainda que as potencialidades da pesquisa (auto)biográfica estão, justamente, na possibilidade de explorar o entrelaçamento entre linguagem, pensamento e práxis social.

Ao se lerem e se darem a ler por meio das cartas, os jovens em privação da liberdade fornecem elementos para interpretações que ultrapassam as temporalidades e as espacialidades da instituição na qual vivem e convivem, em média, por mais de 18 meses. As cartas dos jovens permitem uma leitura dos percursos juvenis e das instituições que concorrem em seus processos de socialização para além dos muros e das grades. Embora não possuam espelho no espaço do confinamento, as escritas de si na privação da liberdade desafiam os jovens a uma prática de construção de si, colocando-os em frente ao "espelho", procedendo com os arquivamentos do eu. Com esse procedimento, relacionam a imagem social àquela que constroem de si próprios, muitas vezes como única forma de responder às inquietudes da sua própria vida e às condições existenciais a que estão submetidos. 


\section{OS ARQUIVAMENTOS DO EU NA PRIVAÇÃO DA LIBERDADE}

Vários autores abordam aspectos relativos aos processos de escrita em contextos prisionais, desde os espaços do confinamento ou da privação da liberdade. Entre eles podemos citar José Machado Pais (2005), Philippe Artières (1998) e Heleusa Figueira Câmara (2001), os quais constituem fonte de inspiração para os aspectos analíticos que pretendemos abordar neste texto. Em contextos diversos, esses autores penetram nas subjetividades de atores sociais considerados inabilitados para a aceitação social plena (Goffmann, 1988), ou seja, sob o estigma de bandidos, de prisioneiros, ou seres encarcerados sem identidade e em conflito com a lei.

Câmara (2001) fez sua incursão pelos discursos prisionais numa casa de detenção do interior da Bahia/Brasil. Em sua pesquisa, a autora observou as representações de vida dos prisioneiros por meio de um projeto que combinou leitura e escrita. Conforme suas palavras, "as escrituras dos internos, respectivamente autorizadas para publicação, mostram autores prisioneiros, em suas relações contratuais de cumprimento de penas, escrevendo sobre si, buscando no prazer criativo o cuidado de si, o fazer escolhas para uma possível organização de suas vidas" (idem, p. 32).

Pais (2005) desenvolveu sua pesquisa abordando trajetórias de 14 jovens. Dentre eles, três encontravam-se em estado de reclusão no Estabelecimento Prisional de Lisboa/Portugal, por conta do que o autor denomina de "ganchos ilícitos". O sociólogo português tomou os apontamentos escritos por um desses jovens, produzidos na prisão e disponibilizados à análise do pesquisador. Para esse autor, ao escrever apontamentos de vida, o jovem privado da liberdade "não trata apenas de reviver o passado, nem de encontrar as lembranças de um passado conservado enquanto tal: a reconstrução do passado é sempre feita através da vivência do presente" (idem, p. 293).

A contribuição de Artières (1998) explora as práticas de arquivamento do eu através da análise dos escritos de um criminoso chamado Nouguier, preso no presídio Saint-Paul de Lyon/França, no fim do século XIX. Com base em uma escrita espontânea e, posteriormente, atendendo ao pedido de um médico, o prisioneiro começou a arquivar sua vida, produzindo um acervo de mais de oitocentas páginas escritas. Nas análises que faz dos dois momentos de escrita de Nouguier, a espontânea e a dirigida a um leitor concreto, Artières observa as similitudes de uma e de outra forma e afirma: "Prática íntima, o arquivamento do eu muitas vezes tem uma função pública. Pois arquivar a própria vida é definitivamente uma maneira de publicar a própria vida, é escrever o livro da própria vida que sobreviverá ao tempo e à morte." (idem, p. 24).

O ponto de conexão que frisamos com o nosso estudo, ao descrever sumariamente as pesquisas anteriormente citadas, encontra-se nas produções discursivas de jovens do sexo masculino, em privação da liberdade e em conflito com a lei. As narrativas de si produzidas em diferentes contextos espaçotemporais possibilitam 
conhecer os trajetos de vida dos sujeitos envolvidos e perceber os aspectos que eles sublinham ao narrarem seus percursos, dados a ler mediante a palavra escrita. Em outras palavras, consoante a Passeggi (2010, p. 112), "a pesquisa (auto)biográfica tem por ambição compreender como os indivíduos [...] e/ou grupos [...] atribuem sentido ao curso da vida, no percurso de sua formação humana, no decurso da história”.

Nas abordagens de Câmara, Pais e Artières, assim como em nossa pesquisa, as escritas de si têm uma direção, um leitor concreto como destino das mensagens comunicadas. Embora a perspectiva do medo e do controle perpasse a publicização das narrativas nas primeiras cartas, os vínculos com o $\mathrm{Si}$, como o principal leitor dos seus escritos, vai, aos poucos, possibilitando uma escrita mais solta com traços fortemente marcados por uma combinação do caráter descritivo com o reflexivo.

Falamos em escritas de si na perspectiva abordada por Foucault (2006), no livro O que é um autor?. No capítulo "A escrita de si", Foucault discorre, especialmente, sobre dois contextos de escrita de si: o caderno de notas e a correspondência. Segundo o autor, "os cadernos de notas, que, em si mesmos, constituem exercícios de escrita pessoal, podem servir de matéria-prima para textos que se enviam aos outros" (idem, p. 145), nesse caso, potencializando as trocas por meio do recurso às cartas.

Posicionando essa afirmação no contexto de nossa pesquisa, observamos os jovens organizando suas narrativas, buscando uma sequência temporal para os fatos, constituindo justificativas para o passado, quase sempre associadas à descrição do delito e à expressão do sentimento de saudades da família. Trata-se de um exercício de evocação da memória, combinando lembrança e esquecimento, à semelhança das funções assumidas pelo caderno de notas referido por Foucault.

Vou falar um pouco da minha vida, fui preso no dia 07 do 07 de 2008, com tendência a ficar um tempo por aqui. Fui julgado, e hoje completa 9 meses que estou no CASE. Esse mês de abril, aguardo a resposta do juiz para sair nos finais de semana. (J6. - abril de 2009)

Meu nome é J5, tenho 19 anos. Estou no CASE pela $2^{a}$ vez. Na primeira vez eu fiquei 1 ano e seis meses, saí e fui para a semiliberdade e fiquei sete meses. Daí eu consegui ir para L.A. Fazia dois meses que eu estava na rua, eu me envolvi num homicídio, daí eu vim parar aqui de novo, faz 1 ano e 9 meses sem sair. Eu caí preso em maio de 2005. Fiquei até outubro de 2006, voltei em julho de 2007 e estou até agora. (J5 - abril de 2009)

Em outra via, podemos relacionar as cartas dos jovens à categoria correspondência desenvolvida no texto de Foucault (2006, p. 149), na medida em que elas não são um simples prolongamento do caderno de notas, mas, sim, "uma maneira de cada um se manifestar a si próprio e aos outros". As escritas de si repousam sobre um solo dialógico. Cada palavra escrita se configura como uma proposta de diálogo. Nessa moldura, cada expressão adquire uma forma de ação e de reflexão. 
As narrativas trazem à luz o horizonte que transcende o dito das proposições linguísticas. O conteúdo expresso não se afasta do antes e do depois. Com base nas cartas, os jovens procederam com uma espécie de paginação da própria vida (Pais, 2005). Ao se apresentarem, construíram narrativas, escolheram palavras, ordenaram fatos e refletiram sobre eles.

Tenho 19 anos, estou cumprindo medida no CASE desde 2005, tive várias oportunidades de estar fora deste lugar. Já fugi três vezes, quando me liberavam para visitar minha família eu não voltava, e assim foi passando todo esse tempo. As pessoas acham que quando a pessoa foi presa, ou privada da sua liberdade, está no fundo do poço, mas eu acredito que cada um pode definir o seu fundo do poço. Se você não tomar uma atitude para reverter esse quadro, estará cavando sempre mais. (J1 - abril de 2009)

Em várias cartas, convocaram a presença dos correspondentes evocando conselhos, fazendo perguntas, buscando a presença do interlocutor, a exemplo do que afirma Foucault (2006, p. 150): "A carta faz o escritor 'presente' àquele a quem a dirige. E presente não apenas pelas informações que lhe dá acerca da sua vida, das suas atividades, dos seus sucessos e fracassos, das suas venturas ou infortúnios; presente uma espécie de presença imediata e quase física”. O sentido no dito sobre si não se reduz ao que está posto no significado semântico das palavras escritas, mas completa-se, ganha força e vivacidade naquilo que está marcado pela motivação da fala e na possibilidade da escuta. A escrita de si está perpassada pela intersubjetividade.

O olhar longitudinal sobre o método escolhido para o desenvolvimento de nossa pesquisa permite observar as potencialidades da escrita na explicitação das subjetividades que envolvem as construções de si de uma juventude marcada pela experiência da privação da liberdade. Com a consciência de si que emerge dos escritos, os jovens mostram as imagens que possuem de si e os rótulos assumidos a partir da situação juvenil no confinamento.

Muitas vezes as minhas lembranças do que vivi vem à minha mente como um filme chato e repetitivo. E essas recordações me fazem sofrer. Poderei me sentir melhor se recordar também dos acontecimentos bons, como me aconselhou uma amiga. Concluí com tristeza que as boas recordações eram raras: presente que eu ganhei na escola, algumas vezes na infância que eu vesti roupas novas; essas recordações são de coisas materiais. Fui pra escola, gostava. Aprendi a ler e escrever com facilidade. Com 19 anos estava ainda viciado e comecei a pensar: viciado não presta pra nada e morre logo. (J3 - abril de 2009)

Nenhum jovem se caracterizou como jovem. As expressões utilizadas para nomearem-se giraram em torno de prisioneiro, jovem detento e, em alguns casos, bandido. Embora esses processos de etiquetagem (Pais, 2004) possam representar os 
discursos sociais produzidos em torno dos jovens em situação de vulnerabilidade social, eles foram possíveis de explicitação por meio da escrita das cartas, sublinhando a afirmação de Foucault (2006, p. 150) ao dizer: "Escrever é, pois, 'mostrar-se', dar-se a ver, fazer aparecer o rosto próprio junto ao outro”. A abertura ao outro pressupõe necessariamente o diálogo. No diálogo é possível manter uma compreensão aberta para enriquecê-la. A subjetividade humana não se fundamenta a si mesma, pois sendo abertura ao outro está sempre remetida ao mundo das relações existentes.

O método da paginação possibilitado pela escrita de si, através das cartas, opera outro procedimento que escapa ao controle do que é expresso nos textos: os arquivamentos do eu.

Impossível seria acompanhar o movimento que cada jovem fez ao abrir e fechar os arquivos da própria vida ou, dizendo de outra forma, ao criar novos espaços para guardar os produtos das suas reflexões, esconder memórias não gratas, depositar na lixeira aquelas situações que escolhem descartar.

Penetrar nos arquivos íntimos de cada jovem exige uma verdadeira operação de rastreamento à medida que, segundo Artières (1998, p. 3), ao arquivar nossas vidas, "fazemos um acordo com a realidade, manipulamos a existência: omitimos, rasuramos, riscamos, sublinhamos, damos destaque a certas passagens". Um pouco de ficção não poderia deixar de se fazer presente nos textos dos jovens, em alguns casos para impressionar os interlocutores e, noutros, como forma de construir uma realidade a partir do lugar distanciado do contexto da própria vida. De acordo com o historiador francês, mediante a prática de arquivar nossas vidas, arrumando, desarrumando ou reclassificando, "construímos uma imagem, para nós mesmos e às vezes para os outros” (idem, p. 2).

Quase inexistem arquivos físicos na posse dos jovens, pois tudo o que levam para o $b_{r e t e}{ }^{7}$ passa pelo controle dos técnicos da instituição. Por esse motivo, a releitura das cartas e a ativação da memória dos escritos na correspondência anterior era recuperada pela inserção do texto digitado na carta-resposta. Os manuscritos dos jovens passaram, muitas vezes, por verdadeiros processos de decifração, incluindo a ilegibilidade das caligrafias até as marcas de destaque impressas por cada autor.

As primeiras cartas dos jovens de nossa pesquisa refletiram um protocolo mais formal, com apresentações de um perfil pessoal e uma breve descrição da trajetória com o delito, indicando, por exemplo, o tempo em que estavam na instituição. Alguns jovens, porém, escaparam da zona de controle e relataram aspectos íntimos de suas trajetórias, logo nas primeiras cartas. Esses movimentos na escrita dos jovens desafiaram-nos à revisão de algumas respostas, em alguns momentos, muito mais ao nível do aconselhamento, do que propriamente tornar a troca de

7 Expressão utilizada para se referirem ao espaço íntimo do quarto, partilhado na maior parte das vezes com pelo menos dois ou mais jovens. 
correspondências como uma entrevista feita de palavras escritas, com espaços-tempos entre o envio e a resposta.

Embora Foucault refira os conselhos como conteúdo comum nos escritos dos correspondentes, procuramos nos afastar desta situação, tendo em vista os objetivos da pesquisa. Procuramos muito mais interagir por meio da colocação de novas perguntas do que de um posicionamento ante as respostas que os jovens buscavam para suas inquietações. Consideramos esse movimento importante para manter o necessário distanciamento. O que fizemos foi desafiá-los a colocar em revista seus dias no espaço-tempo de confinamento e, ao fazerem isso, arquivar a própria vida. Para Foucault (2006, p. 152), “o trabalho que a carta opera sobre o destinatário, mas que também é efetuado sobre o escritor pela própria carta que envia, implica, pois uma 'introspecção', mas há que entender esta menos como uma decifração de si por si mesmo do que como uma abertura de si mesmo que se dá ao outro”.

Neste sobrevoo sobre os dados empíricos, percebemos ainda que uma (re)produção discursiva da comunidade terapêutica se mostrou fortemente presente e por um longo período, assim como uma autoculpabilização, com indicativos que as respostas e a superação dos conflitos gerados pela dependência química estavam dentro de si. À medida que o tempo passava e que o vínculo com o leitor e respondente de suas cartas se estabelecia, vários jovens foram se desprendendo das formalidades e começavam a interagir com os pesquisadores, fazendo perguntas e/ ou comentários em relação às respostas que recebiam.

Além disso, a partir da segunda ou terceira carta, tornou-se comum observar narrativas de si para si, remetendo os escritos a uma autoleitura. Recorrendo novamente a Foucault (2006, p. 145), podemos evocar que "a carta enviada atua, em virtude do próprio gesto da escrita, pela leitura e releitura, sobre aquele que recebe”. No caso desta pesquisa, cada carta tinha um duplo remetente: os pesquisadores e o próprio autor da carta.

\section{OS ECOS DAS ESCRITAS DE SI}

O exercício da escuta dos ecos das escritas de si, protagonizadas pelos jovens da nossa pesquisa, exige-nos o desenvolvimento e aplicação de competências que se aproximam de uma atitude detetivesca, em direção à decifração de enigmas.

As identidades culturais envolvidas na trajetória de cada jovem, associadas às culturas prisionais apropriadas na experiência do confinamento, manifestam-se na forma como cada um expressa e traduz a realidade. Os signos evocados em cada situação, em geral, apresentam-se de forma cifrada, indicando as representações construídas sobre o vivido, quer nos contextos individuais, quer nos contextos coletivos. Nosso papel, como pesquisadores, é, pois, ir em busca da decifração dos enigmas do cotidiano dos jovens que nos emprestam suas palavras para análise. Em outras palavras, podemos afirmar que as representações atuam como "matrizes 
geradoras de condutas e práticas sociais, dotadas de força integradora e coesiva, bem como explicativa do real" (Pesavento, 2008, p. 39).

Ao recortar algumas unidades de sentido das cartas dos jovens e organizá-las em torno de três categorias - percepções de si, relações com os tempos do confinamento e projetos de futuro -, procuramos uma leitura, muitas vezes, através de "pistas mudas" (Ginzburg, 2009). Portanto, o desafio que se coloca é dar voz às nossas fontes, pela descrição, análise e interpretação.

\section{AS PERCEPÇÕES DE SI}

Conforme afirmou Câmara (2001, p. 211), “o espaço da prisão tira a identidade do prisioneiro, que passa a ser conhecido pelos administradores carcerários, visitantes e comunidade em geral, pelo delito". Embora haja tentativas de dissipar os rótulos que acompanham a história do CASE e de redirecionar as próprias ações para o caráter ressocializador, a instituição carrega as representações da antiga FEBEM e ainda é nomeada como tal pelos moradores da comunidade do seu entorno e por vários jovens. A identidade de prisioneiro é recorrente em várias narrativas dos jovens.

As cartas de J7, 19 anos, deixam ecoar, além de sua identidade de prisioneiro, as suas identificações como usuário de crack, como autor de furtos e ainda como fugitivo: "Voltei a usar drogas, comecei a roubar de novo, com ainda mais frequência e por outras sete vezes retornei ao CASE" (abril de 2009). A volta ao mundo das drogas confere-lhe a identidade de dependente químico ou de viciado, como ele próprio referiu numa carta; o recurso ao roubo para sustentar o vício o inclui no estatuto de jovem em conflito com a lei; e as novas entradas na instituição, devido às sete fugas, que lhe atribuem, temporariamente, a identidade de foragido.

O sonho com uma vida fora da instituição é pauta de suas cartas ao expressar: “todas as noites sonho com a minha liberdade". Seus poemas, registrados ao final de cada carta, retratam seus sentimentos e perfazem sínteses de seus pensamentos, conforme ele próprio narrou:

Bem, resumindo tudo o que eu escrevi, fica mais ou menos assim:

Sou um triste prisioneiro

Herdeiro da solidão

Sou forte fisicamente, mas fraco de coração.

Quando penso no mundão,

Lembro que amei e fui amado,

Mas por causa do meu erro

Hoje sou um triste prisioneiro que sofre calado.

(J7 - abril de 2009) 
Contextualizando as palavras do poema de J7, com as narrativas registradas nas cartas, é possível reconhecer outras percepções de si, dadas pelo perfil do jovem solitário, preso aos seus pensamentos, assim como do filho que faz a mãe sofrer, do irmão preocupado e do namorado que frustrou as expectativas da amada, recaindo no mundo das drogas e do crime.

Ginzburg (2009, p. 177) nos fala que "se a realidade é opaca, existem zonas privilegiadas - sinais, indícios - que permitem decifrá-la”. A identidade de filho é uma dessas zonas, presente em todas as cartas, mostrando o lado sensível dos meninos que cometem atos infracionais e o lugar da mãe como um refúgio seguro e em direção à liberdade tão sonhada. As mães são sempre lembradas e, em alguns casos, comparadas a verdadeiras guerreiras, como relata J1, também com 19 anos:

Eu e meu irmão estamos privados de nossa liberdade e somos dependentes químicos. Meu pai é alcoólatra, mas minha mãe, "minha guerreira", é uma das pessoas que sempre estiveram do meu lado. Imagine a dor dessa pessoa, e essa pessoa é um dos motivos da minha mudança. Hoje entreguei minha vida nas mãos de Deus, terei uma nova oportunidade e não desperdiçarei, pois tenho comigo uma meta. Essa meta é dar uma alegria para a minha guerreira, mostrar para ela que tudo o que ela fez por mim não foi em vão. (J1 - abril de 2009)

O encontro com a espiritualidade como depositária da esperança de vencer o vício marca a identidade de um jovem que crê em Deus e que tem fé. O jovem J1 tem convicção de que o destino parece ter marcado suas escolhas que lhe afastaram do caminho, porém, a fé em Deus lhe aproximará do seu projeto de futuro:

Tenho desejo de construir minha família, ter meu emprego e construir uma vida perto de Deus. [...] Talvez tudo isso tivesse que acontecer em minha vida. Perdi tudo o que eu tinha de bens materiais, perdi pessoas que devido aos meus atos se afastaram de mim. Tenho que construir tudo de novo, não será fácil. Não tenho nada de mais importante para fazer e tenho certeza que Deus me mostrará o caminho. (J1 - abril de 2009)

Não há dúvidas de que essas escritas (de si) produzem consciências (de si), considerando que "escrever sobre si e para si, para o duplo, é como pensar em voz alta, a fim de patentear ou não o que se fez, o que se quer" (Câmara, 2001, p. 170). $\mathrm{O}$ jovem J1 narra suas dificuldades de aprendizagem como consequência do uso de drogas e traça objetivos para superação, fazendo emergir também a identidade de aluno:

A vida que eu levei deixou feridas e sequelas. Tenho muitas dificuldades em aprendizado hoje, muitas vezes não consigo gravar leituras por muito tempo. Decorar, então, muito difícil. Mas, com a ajuda da escola e professores, vou exercitando essas áreas em que tenho dificuldades. Afinal, ninguém nasceu 
sabendo, todos fomos aprendendo com o tempo, e com dedicação e esforço alcançarei todos os meus objetivos. (J1 - abril de 2009)

Muitos ecos das escritas de si estão ainda à espera da decifração e da capacidade de ler e escutar mesmo quando as pistas são invisíveis ou mudas, porém, para o contexto aqui narrado, esses são os ecos possíveis e que ganham voz por meio da interpretação que deles fazemos, ancorados na premissa de que "o escrever possibilita traçar pontos de visitação, de fuga, de consolação e de indignação e está sempre se fazendo" (Câmara, 2001, p. 167).

\section{ENTRE O ANTES E O DEPOIS: OS TEMPOS DO CONFINAMENTO}

Melucci e Fabrini (2002, p. 69-73) afirmam que as identidades juvenis se constituem na consciência do tempo e do espaço, que fornece as coordenadas dentro das quais pode crescer a capacidade efetiva de fazer experiência. Segundo os pesquisadores italianos, cada ação se desenvolve e se resolve em um tempo, acontecendo nos limites espaciais impostos por um ambiente (idem, p. 69-73).

O tempo do confinamento é transversalizado pelo antes e pelo depois, fica espremido entre ambos e, na maior parte das vezes, é um tempo estendido que demora a passar. Como elemento constitutivo da experiência humana e, portanto, difícil de ser definido, Melucci (2004) refere-se à experiência do tempo como fluida e envolvente, com densidades e dimensões pouco consideradas em nossas definições, mas traduzidas por metáforas ou mitos por diferentes culturas. $\mathrm{O}$ círculo, a flecha, o ponto e a espiral são metáforas do tempo utilizadas para definir algumas dimensões de tempo que aparecem na história das culturas.

As narativas expressas nas cartas seguem uma cronologia, são ricas em detalhes e consoantes a metáfora da flecha.

Tudo começou quando eu tinha 7 anos. Brincava muito com meus amigos.

Nós éramos muito felizes, brincávamos de pique-esconde. [...] Quando eu tinha 10 anos comecei a olhar os meus outros amigos usar drogas e roubar. Nunca passou pela minha cabeça que um dia eu iria usar drogas e roubar. Mas um dia eu experimentei e gostei. Comecei a usar, tinha alguns momentos que eu não tinha droga e ficava com muita vontade. Com o passar dos dias comecei a usar outras drogas como maconha e cocaína, e depois com o passar dos anos conheci um grupo de drogados e comecei a andar com eles. (J3 - abril de 2009)

Entretanto, as setas do tempo flecha são interceptadas por tempos ziguezagueantes e velozes fazendo surgir os contratempos, nos quais a experiência com o mundo das drogas e os conflitos com a lei redirecionam os percursos de vida (Pais, 2005, p. 63). 
Dez de setembro de 2008, mais um homicídio. Eu já tive quatro homicídios, e já fica, o pensamento já fica mais muito louco, fico imaginando fazer um assalto de novo. Já falei com meus cupincha para assaltar de novo carros, casa, mercado. É fazer a mão dos contra. Já mataram um deles e me avisaram que pegaram um deles, já fiquei aliviado. (J4. - abril de 2009)

Lá, na rua fico olhando. Lá, na rua vejo carro passando, e penso: aqui parece que tudo é mais interessante. Lá, logo que fico pensando que lá fica mais lindo e na janela fico olhando e tudo o que eu aprendi. Lá na rua é diferente e a cada dia fica mais chato e tudo parece mais lento o dia aqui e na janela fico ali. (J4.abril de 2009)

Nos seus trânsitos pelas rotas do risco, os jovens deparam-se com as experiências do tempo, seja o contraindo, vivendo a toda, seja o dilatando na espera alucinógena para a conquista da liberdade. O jovem J1 narra um tempo cíclico que não passa e que consome vagarosamente suas horas de confinamento. As noites assemelham-se à eternidade, o dia à rotina da repetição, porém, em nenhum dos casos, conforme sua afirmação, "as grades não prendem nossos pensamentos".

Quinze para a meia-noite e já estou de toca, que frio de lascar, só que um loquinho me falou que eu era o próximo da lista dele, quero ver a cara dele, cai o sistema.

UMA HORA da manhã, a mente já não consegue raciocinar direito, que tá fazendo aqui, só o vento que tá forte, maior loucura, são duas e vinte da manhã lá na faixa tem uma mina passando fazendo o maior esparro, só podia ser a K., a F. e a D., ficaram que ficaram até uma hora.

4 HORAS ouço dois tiros, se pá, mataram mais um, só silêncio aqui no sistema, só eu e a sorte fica no peito.

É quase 5 HORAS e ainda não deu para dormir, para tudo o que é assim, sei lá o que tá acontecendo comigo, que dor de cabeça, tá latejando, só deu no rádio que é 6 HORAS e passou a noite, tô tentando dormir.

8 HORAS da manhã, aí levanto, pego o café e depois vou para a escovação.

11 HORAS ligo pro meu pai, só meu pai tá doente, a maior preocupação, que manhã mais demorada. (J4. - agosto de 2009)

O horizonte da espera encontra-se significativamente dilatado e anula, praticamente, o espaço da experiência. A contração do tempo emerge da antecipação do futuro e encolhimento do tempo de viver a juventude, por conta das experiências de 
risco. Nos contextos prisionais, o presente ganha sentido ao ceder lugar aos projetos de futuro, os quais preenchem o vazio provocado pela queima de etapas, consumida vorazmente pela experiência com a drogadição e com o mundo do crime.

Estar aqui nesse lugar é muito ruim, é muitas coisas acontecendo e existem muitas dificuldades. [...] Estando aqui a pessoa foge da realidade do mundo e se esquece dos problemas da família às vezes e quando sabe de algo abala totalmente a estrutura que tinha conseguido obter. (J1 - abril de 2009)

As percepções de si revelam a participação efetiva desses jovens em comunhão de sentido, o que marca o tempo histórico em que estão inseridos. $\mathrm{O}$ mundo em que vivem no presente é o mundo ao qual pertencem. É esse mundo que determina as suas percepções e suas possibilidades. Ao tentar explicar o presente, evocam memórias do passado e vislumbram o futuro. As narrativas são vivências do passado, por meio do qual o presente se concretiza e o futuro se antecipa. Nesse caso a possibilidade de transcender o presente é marcada pela abertura enquanto marca ontológica do ser humano. Isso quer dizer que o ser humano vive à esfera do sentido e, enquanto tal, a possibilidade de vir a ser é sua marca estrutural.

\section{NOS PROJETOS DE FUTURO O ALIMENTO PARA SUPORTAR O PRESENTE}

Os projetos de futuro dos jovens são recheados de sonhos: abandonar as drogas, concluir a escolarização obrigatória, conquistar um emprego, constituir uma família, recuperar o tempo perdido e fazer a mãe feliz. Não dá para desconsiderar a experiência vivida no confinamento, pois, nos interstícios das normas e dos regulamentos do sistema, organizado para a ressocialização dos jovens em conflito com a lei, acontecem as socializações informais que produzem as aprendizagens informais (Pais, 2005, p. 315).

Mas para mim ter sido preso foi uma grande lição de vida, pois estou muito mudado, com outros pensamentos. Antes de eu ter sido preso eu era um "marginal”, usava maconha, já era um viciado. Mas hoje não gosto nem do cheiro, pois reconheci que isto é só ilusão. (J6 - abril de 2009)

As socializações decorrentes dos espaços intersticiais das instituições participam das trajetórias dos nove jovens investigados. Embora indiretamente, a experiência do confinamento e da interação com as histórias de vida dos outros jovens acaba por influenciar os seus projetos de futuro. As narrativas das cartas indicam que são os sonhos e a possibilidade de construção de outra realidade que nutrem o presente, o espaço e o tempo da reclusão.

Quero sair, arrumar estudos, um emprego e uma namorada, dar valor a minha família, que mesmo eu tendo errado veio me visitar, e eles ainda apostam em 
mim. Quero dar muito orgulho para a minha mãe que sempre me deu conselho, mas eu nunca ouvia. Estou muito arrependido do que fiz, quero esquecer o passado e pensar daqui pra frente. Não penso mais maldade, graças a Deus, quero sair e até ir pra Igreja. Pode parecer brincadeira, mas não é. A vida do crime não convém. Tem um ditado que diz: "o crime financia os seus sonhos, depois cobra um alto preço”. (J6 - abril de 2009)

Diferentemente de outros jovens, em situações sociais diversas à privação da liberdade e não situados em zonas de vulnerabilidade, os jovens em conflito com a lei relatam um presente quase ausente. Ao mesmo tempo em que os projetos de futuro se mostram afirmativos de outra trajetória possível, a realidade é um tanto desoladora, visto que apenas um dos nove jovens investigados pode ser considerado ressocializado e devolvido para a sociedade em condições de gerir a própria vida com autonomia.

Eu no momento estou me ocupando o máximo que eu posso para passar o tempo, eu estou me esforçando para acabar o Ensino Médio, no momento eu estou cursando o $3^{\circ}$ ano do Ensino Médio e os projetos que eu estou pensando em sair daqui e constituir uma família e fazer se possível uns cursos profissionalizantes, e arrumar um bom emprego porque pra quem quer uma família precisa de um bom emprego. (J5 - abril de 2009)

Uma ambiguidade perpassa os contextos narrativos, informando uma aversão à instituição responsável por seus processos de socialização, ao mesmo tempo em que representa segurança e proteção em relação a um mundo externo cheio de riscos, convites, tentações.

Me desculpe, mas eu vou falar bem a verdade: eu prefiro estar aqui do que estar lá fora. Sabe por quê? Eu não sou um menino mimado, se eu tivesse na rua eu estaria roubando ou até mesmo morto. Aqui eu tenho um teto e uma cama para dormir, e as donas e as professoras são legais, elas me ajudam e me corrigem na hora que eu estou errado, coisas que eu não tenho lá fora. (J8 - abril de 2009)

O paradoxo da escolha situado por Melucci (2004, p. 62-64) "confronta o indivíduo com uma complexa variedade de escolhas e, ao mesmo tempo, oferece pouca ajuda sobre as opções que devem ser selecionadas". Quais as opções de escolha que restam a estes jovens, por exemplo, quando pegam externa? Conforme relata J2, jovem assumidamente gay, sofrendo os preconceitos de sua opção sexual no espaço institucional, tanto pelos representantes do mundo adulto como dos seus pares: "O meu pai não me quer, minha vó também. Eu saio daqui e desço perto do beco. Tenho que ser muito forte para resistir. Nem sempre eu resisto" (relato oral - janeiro de 2010). Nesses casos, os impasses do presente é que tornam o futuro ausente, pois as escolhas, ou seja, a resistência à droga, recolocam o jovem em situação de vulnerabilidade e em conflito com a lei, pois, para sustentar o vício, J2 precisa roubar e prostituir-se, repetindo o ciclo de sua trajetória anterior ao confinamento. 
Apesar dessas adversidades, o sonho acontece e a materialidade dele se efetiva parcialmente - nem que seja através dos espaços (auto)biográficos, tendo as cartas como suporte -, sublinhando as afirmações de Câmara (2001, p. 167): "considerando o mundo como um conjunto de sintomas, cuja doença se confunde com o homem, o escritor é médico de si próprio e do mundo".

\section{CONSIDERAÇÕES FINAIS}

As escritas e as percepções de si revelam a participação efetiva de jovens em comunhão de sentido, o que marca o tempo histórico em que estão inseridos. Heidegger já afirmava que a abertura é uma das marcas constitutivas do ser mundano. Isso permite o eu ir ao encontro do outro e projetar-se para o futuro. Tal processo se faz como disposição. O modo de ser da disposição ocorre como projeção. É nesse caminho que cada indivíduo se descobre como ente temporal capaz de encontrar um sentido para a sua vida futura.

A temporalidade é um modo de ser que coloca o ser humano na dimensão do tempo. Isso quer dizer que o sentido do tempo presente nas escritas de si se torna possível de verificar na temporalidade, que é marca constitutiva de todo ser humano independentemente de sua condição existencial e de sua participação. Assim, os jovens que participam nesse modo de ser com suas narrativas são lançados aos desafios do tempo. Como movimento da temporalidade, o passado os encobre, o presente os torna efêmeros, mas o futuro abre-se como horizonte de possibilidades.

As escritas de si configuram-se como condição de possibilidade para a construção da subjetividade. "Arquivar a própria vida é se pôr no espelho, é contrapor à imagem social à imagem íntima de si próprio e, nesse sentido, o arquivamento do eu é uma prática de construção de si mesmo e de resistência" (Artières, 1998, p. 11). Contudo, isso não ocorre de modo solipsista, do diálogo da alma consigo própria, ao estilo platônico. A relação dialógica consiste na abertura ao outro. O eu é uma unidade de sentido que guarda em si sua singularidade.

Enfim, a atividade de quem interpreta implica sempre uma abertura ao que foi narrado para que não haja distorção da mensagem. $O$ intérprete como investigador tem o desafio de romper a barreira do silêncio mediante a capacidade de escutar. Evocando Passeggi (2010, p. 112), podemos dizer ainda que "não se busca a 'verdade objetiva', pois se tem consciência de que a 'realidade' passa, obrigatoriamente, pela mediação dos sistemas simbólicos, constitutivos do imaginário social, que é, por sua vez, subjetivado pelos indivíduos". Assim, a interpretação das narrativas (auto)biográficas dos jovens da pesquisa não ocorreu simplesmente com a aplicação metódica de técnicas, uma vez que a 
atitude interpretativa não se trata de um invólucro que guarda um sentido que pode ser simplesmente reproduzido por outra narrativa. Ao contrário, tecemos uma metanarrativa, construída pelos ecos diretos e indiretos dos interlocutores - empíricos e teóricos - que evocamos para o diálogo, incluindo também nossa própria voz, no lugar de pesquisadores.

\section{REFERÊNCIAS}

ArTIÈRES, Philippe. Arquivar a própria vida. Revista Estudos Históricos, v. 11, n. 21, 1998. Disponível em: <http://virtualbib.fgv.br/ojs/index.php/reh/article/view/2061/1200>. Acesso em: 28 maio 2010.

CÂMARA, Heleusa F. Além dos muros e das grades (discursos prisionais). São Paulo: EDUC, 2001.

Chartier, Roger. O mundo como representação. Estudos Avançados, São Paulo: Instituto de Estudos Avançados, USP, v. 5, n. 11, jan./abr. 1991.

. A história cultural: entre práticas e representações. Tradução de Maria Manuela Galhardo. 2. ed. Lisboa: Difusão Editorial S.A., 1988.

FoucAult, Michel. O que é um autor? Lisboa: Editora Passagens, 2006.

GinzBuRG, Carlo. Sinais: raízes de um paradigma indiciário. In: Mitos, emblemas, sinais. Tradução de Federico Carotti. 2. ed. São Paulo: Companhia das Letras, 2009.

Josso, Marie-Chistine. Experiências de vida e formação. Natal: EDUFRN; São Paulo: Paulus, 2010.

Melucci, Alberto; Fabrini, Ana. L'età dell'oro: adolescenti tra sogno ed esperienza. Milão: Feltrinelli, 2000.

Melucci, Alberto. O jogo do eu. São Leopoldo: Ed. da Unisinos, 2004.

PAIS, José M. Introdução. In: PAIs, José M.; BLAss, Leila Maria da S. (Org.). Tribos urbanas: produção artística e identidades. São Paulo: Annablume, 2004.

. Ganchos, tachos e biscates: jovens, trabalho e futuro. Porto: Âmbar, 2005.

Passegui, Maria da C. Narrar é humano! Autobiografar é um processo civilizatório. In: PAsseggi, Maria da Conceição; Silva, Vivian Batista da (Org.). Invençôes de vidas, compreensão de itinerários e alternativas de formação. São Paulo: Cultura Acadêmica, 2010.

Pesavento, Sandra J. História \& História Cultural. Belo Horizonte: Autêntica, 2008.

STECANELA, Nilda. Jovens e cotidiano: trânsitos pelas culturas juvenis e pela escola da vida. Caxias do Sul: EDUCS, 2010. 


\section{SOBRE OS AUTORES}

Nilda Stecanela é doutora em educação pela Universidade Federal do Rio Grande do Sul (UFRGS). Professora da Universidade de Caxias do Sul (UCS) e da Rede Municipal de Ensino de Caxias do Sul.

E-mail: nildastecanela@terra.com.br

Evaldo Antonio Kuiava é doutor em filosofia pela Pontifícia Universidade Católica do Rio Grande do Sul (PUC-RS). Pró-reitor acadêmico e professor da Universidade de Caxias do Sul (UCS).

E-mail: eakuiava@ucs.br

Recebido em maio de 2011

Aprovado em julbo de 2011 


\section{NILDA STECANELA E EVALDO ANTONIO KUIAVA}

\section{As escritas de si na privação da liberdade: jovens em conflito com a lei arquivando a própria vida}

O foco deste trabalho volta-se para os percursos reflexivos produzidos numa pesquisa realizada com jovens em conflito com a lei e socializados em contextos de privação da liberdade. Tem como objetivo analisar as representações que nove jovens, situados na faixa etária dos 18 aos 21 anos, têm sobre sua situação juvenil, considerando as narrativas de si como material privilegiado para reflexão. Procura escavar as subjetividades construídas nos processos de estigmatização associados aos percursos pelas rotas do risco, assim como os indícios e o grau de identificação que cada jovem tem com suas identidades enquanto: jovens, alunos, presos ou outras. Considera como cenário uma instituição de caráter socioeducativo, localizada no interior do estado do Rio Grande do Sul. A (auto)biografia utilizada como metodologia na construção dos dados valeu-se da carta como suporte para as escritas de si, através da qual os jovens produzem narrativas sobre o cotidiano juvenil na privação da liberdade.

Palavras-chave: escritas de si; jovens em privação de liberdade; narrativas (auto) biográficas.

\section{Deprived of freedom self narratives: young people in conflict with law keeping a file on their own lives}

The focus of this work is based on reflections produced during a piece of research done with young people who are in conflict with law, and socialized in deprived of freedom contexts. Its aim is to analyze representations that nine young individuals, from 18 to 21 years old, have about their situation, considering self narratives as privileged material for reflection. It tries to find subjectivities built during processes of stigmatization associated to ways trough risk routes, together with traces and the degree of identification each young individual has with his/her identities as: young people, students, prisoners, and others. It considers as scenery a socio-educative institution, located in the state of Rio Grande do Sul. The autobiography used as methodology in the building of data made use of the letter as a support for self narratives, through which young people produce narratives about everyday life and freedom privation.

Keywords: self narrative; young people deprived of freedom; (auto)biographical narratives. 


\section{Las escrituras de sí en la privación de la libertad: jóvenes en conflicto con la ley archivando su propia vida}

El foco de este trabajo se vuelve hacia los recorridos reflexivos producidos en una investigación realizada con jóvenes en conflicto con la ley y socializados en contextos de privación de la libertad. Tiene por objetivo analizar las representaciones que nueve jóvenes, situados en la franja de edad entre los 18 y los 21 años, tienen sobre su situación juvenil, considerando las narrativas de si como material privilegiado para reflexión. Intenta escavar las subjetividades construidas en los procesos de estigmatización asociados a los recorridos por las rutas de riesgo, asi como los indicios y el grado de identificación que cada joven tiene con sus identidades en cuanto a: jóvenes, alumnos, presos y otras. Considera como escenario una institución de carácter socioeducativo, localizada en el interior de Rio Grande do Sul. La (auto)biografía utilizada como metodología en la construcción de los datos se valió de la carta como soporte para las escrituras de sí, a través de la cual los jóvenes producen narrativas sobre el cotidiano juvenil en la privación de la libertad.

Palabras clave: escrituras de si; jóvenes en privación de libertad; narrativas (auto) biográficas. 